\title{
Plant-based nanoparticles prepared from protein containing tribenuron-methyl: fabrication, characterization, and application
}

\author{
Moslem Heydari ${ }^{1}$, Ali Reza Yousefi ${ }^{*} \mathbb{D}$, Nasser Nikfarjam² ${ }^{2}$ Abbas Rahdar ${ }^{3}$, George Z. Kyzas $^{4}$ and \\ Muhammad Bilal ${ }^{5}$
}

\begin{abstract}
Background: Tribenuron-methyl is a registered herbicide for broad-leaf weed control in wheat, however, low solubility in water and reacting with hard water's ions could substantially decrease its efficacy. The present work aimed to enhance the dispersing and bioactivity of this herbicide by developing nanoparticles using zein as a promising nanodelivery system and to assess the effects of nanoparticles on the efficacy of tribenuron-methyl in the suppression of Convolvulus arvensis as a problematic weed in wheat fields.
\end{abstract}

Results: Based on SEM analyses nanoparticles sizes were 80-120 nm. DLS results showed an average size of $170 \mathrm{~nm}$ for tribenuron-methyl zein-based nanoparticles (TMZNP-5). The entrapment efficiency (EE\%) of tribenuron-methyl inside the zein nanoparticles was ca. 81\% \pm 3 . Five-week after application of tribenuron-methyl nanoparticles on $C$. arvensis, it was able to reduce the dry weight (53\%), acetolactate synthase (ALS) enzyme activity (82\%), and plant height (77\%) of $C$. arvensis as compared with untreated plants. Additionally, tribenuron-methyl used in nanoparticles at the half rate of the recommended dose had the same efficacy as commercial tribenuron-methyl.

Conclusion: Based on these results, zein nanoparticles can be potentially utilized as nanocarriers for enhancing the solubility of tribenuron-methyl to further enhance its bioavailability and performance on sensitive weeds.

\section{Highlights}

- Tribenuron-methyl-loaded zein nanoparticles synthesized.

- TM-loaded zein nanoparticles characterized by DLS, FTIR, SEM.

- The TM's drug encapsulation efficiency (EE\%) within the nanoparticles was ca. $81 \% \pm 3$.

- F127/VPA and lignin/VPA microemulsions were tested for their cytotoxic activity.

- Use of nanoparticles containing tribenuron-methyl (TMZNP-5) herbicides had a significant effect on weed control.

- After 5 weeks, TMZNP-5 was able to completely suppress the C. arvensis.

Keywords: Herbicide, Convolvulus arvensis, Weed, Wheat, Zein nanoparticle

\footnotetext{
*Correspondence: yousefi.alireza@znu.ac.ir

${ }^{1}$ Department of Plant Production \& Genetics, University of Zanjan, 4537138791 Zanjan, Iran

Full list of author information is available at the end of the article
}

\section{Background}

Nowadays, weed competition results in a $10-100 \%$ reduction in crop yields [1]. Conventional control methods have long been used, including mechanical control 
(such as tillage, hand pulling), biological control, and chemical applications in agricultural environments [2]. Each of the conventional methods of weed control has its strengths and weaknesses, which makes the use of some methods more popular with farmers and others less so chemical weed control is still the main method of weed control after more than seven decades [3]. Herbicides play role in the productivity and safety of food production by cost-effectiveness, and reduction of labor costs, as well as saving on land preparation [4].

Sulfonylurea is one of the largest families of selected herbicides, which includes a large number of different herbicides for weed control [5-8]. Herbicides in this chemical family inhibit the biosynthesis of the three essential amino acids valine, leucine, and isoleucine by inhibiting the enzyme acetolactate synthase (ALS) [9]. Tribenuron-methyl [(methyl2-(4-methoxy6-methyl-1,3,5-triazin-2-yl) methylcarbamoyl sulfamoyl benzoate)] is one of the most commonly used selective herbicides in the sulfonylurea chemical family. It has been registered for control broad-leaf weeds in cereals mainly wheat, barley and, triticale [10]. Low solubility in water and reacting with hard water's ions could substantially decrease its effectiveness. There are several solutions to such problems, one of which is using nanotechnology and reducing particle size.

In nanoscale which is basically water-soluble, the rate of uniform dissolution and dispersion increases [11]. Recently, nanotechnology was discovered owing to its potential at revolutionizing the agricultural industry. Efficacy has been improved by pesticides and herbicides with nano-encapsulation [12] with the even dispersion and adherence of actives to the leaf surface. Several nanostructured materials in the production of agricultural chemicals (herbicide, pesticides, and chemical fertilizers) due to their features including low toxicity, high biodegradability, high recyclability, low cost, quick and easy preparation, good absorption water, and its reversible properties have been used as carriers of active ingredients in herbicides and, pesticides [13, 14]. Owing to their very high surface-to-volume ratio, they create an integrated coating on the leaves and also improve the emission properties in the soil, which has increased the interest of those interested in using nanomaterials in agriculture [15-17]. One of the types of nanomaterials is biopolymers such as natural proteins nanoparticles that are extensively utilized in the pharmaceutical and food industry these days $[18,19]$. Recently, biopolymer-based nanoparticles have been extensively utilized in the drug delivery system. Within drug delivery systems the dissolution rate of drugs is incremented by increasing the surface area of the drug and the corresponding carrier. Plant proteins-based carriers present several advantages over animal lipid, proteins, or synthetic polymer as a result of their availability, biodegradability, and high drug-binding capacity [20-22].

Zein is a plant protein (extracts from Zea mays) with a molecular weight of about $40 \mathrm{kDa}$ that due to properties such as biodegradability, biocompatibility, nontoxicity, and economic reasons has drawn increase to use for different purposes including oral delivery of peptides and proteins, DNA transfection, vaccine delivery, and scaffold for tissue engineering [23-27]. It can be simply transformed into various structures and shapes such as microsphere, films, micelles, nanoparticles, fibers, and gels [28, 29], so zein could be an alternative for encapsulation carriers to deliver nutrition and drugs. According to earlier studies, biopolymer-based nanoparticles (e.g., zein) possessed more hydrophilic groups as well as a smaller size and displayed good bioactivity and solubility [25-30]. On the one hand, the use of polymeric nanoparticles have been introduced as ideal nanocarrier systems for delivery of hydrophobic agents to protect against degradation, and the controlled cargo release at the optimal rate with an improvement of its bioavailability [31, 32]. In this case, polymeric nanoparticles are formed based on the procedure governing on formation of phospholipids in water. Phospholipids are amphiphilic molecules with water-soluble groups and oil-soluble tails [24-27]. With this in mind, this work was initiated to prepare zein nanoparticles as well as zein nanoparticles loaded with tribenuron-methyl and then to investigate the possible effects of these nanoparticles on tribenuron-methyl efficacy on Convolvulus arvensis, as a problematic weed in wheat fields.

\section{Material and method \\ Material}

DuPont Far East Inc., New Delhi, India, supplied a technical scruple of tribenuron-methyl (methyl 2-(4-methoxy-6-methyl-1,3,5-triazin-2-yl)) (95\% purity). It was used as received. Tween 80 and acetone were purchased from Merck Co, and also purified a-zein was bought from Acros Organics (Morris Plains, NJ) and dissolved in ethanol (70\% (v/v); 200 Proof, Decon Laboratories, King of Prussia, PA). It was utilized as the dispersing phase. Merck Chemical Co provided Na-pyruvate, $\left(\mathrm{NH}_{4}\right)_{4} \mathrm{SO}_{4}, \mathrm{ZnSO}_{4}, \mathrm{MnSO}_{4}$, naphthol-1, and $\mathrm{HCl}$. Also 2, 2-diphenyl-1-picrylhydrazyl (DPPH) was prepared from Sigma-Aldrich. Doubly distilled, deionized Millipore water was utilized. Also, dialysis bags were bought from SERVAPOR. 


\section{Fabrication of tribenuron-methyl-loaded zein nanoparticles}

Zein $(0.66 \mathrm{~g})$ was dissolved in $25 \mathrm{~mL}$ aqueous acetone solutions $(70 \% \mathrm{v} / \mathrm{v})$ and stirred with a magnetic stirrer for $24 \mathrm{~h}$ at room temperature till obtaining a homogeneous solution and tribenuron-methyl (TM) was added then to the zein solution (first solution) [33]. Then, $0.75 \mathrm{~g}$ of Tween 80 was dissolved in $25 \mathrm{~mL}$ PBS (0.1 M pH=4) stirred with a magnetic stirrer for $30 \mathrm{~min}$ at room temperature (second solution). This was followed by adding the zein solution dropwise into the second solution while moderately stirring [34] and finally acetone was removed under vacuum rotary evaporation. Three different TM amounts $(0.016 \mathrm{~g}, 0.033 \mathrm{~g}$, and $0.066 \mathrm{~g})$ were used in the formulation to obtain three zein nanoparticles with different TM content which were coded TMZNP-2.4, TMZNP-5 and TMZNP-10, respectively, in which the number refers to the weight percent of TM to zein content (Scheme 1).

The freshly prepared TM-loaded nanoparticles in solutions were exposed to characterizations such as encapsulation efficiency and particle size measurements. The specimens were freeze-dried for release profile and other measurements and stored at $-18{ }^{\circ} \mathrm{C}$ for further assay. Besides TM-loaded zein nanoparticles, TM-free zein nanoparticles were prepared as a control.

\section{Characterization \\ Physico-chemical characterization of TM-loaded zein nanoparticles}

Dynamic light scattering (DLS) was conducted utilizing a commercial laser light scattering instrument (DelsaMax PRO, Beckman Coulter Instruments) with a $90^{\circ}$ scattering angle at $25^{\circ} \mathrm{C}$. Also, the SEM images of nanoparticles were acquired using an AIS-2100 scanning electron microscope, Seron Technology, operating at $15 \mathrm{kV}$. The nanoparticles dispersions were adjusted on a clean glass slide and dried. Then, they were vacuum coated with gold before imaging.
Thermal stability of zein and TM-loaded nanoparticles were measured by thermogravimetric analysis (TGA/ SDTA 851, Switzerland) under $N_{2}$ flow of $20 \mathrm{~mL} \mathrm{~min}{ }^{-1}$ with a heating rate of $10{ }^{\circ} \mathrm{C} \mathrm{min}{ }^{-1}$ in a range of ambient temperature to $600{ }^{\circ} \mathrm{C}$.

To prepare pellets of TMZNPs, ca. $2 \mathrm{mg}$ of zein, and tribenuron-methyl samples separately, $200 \mathrm{mg}$ of spectroscopic grade $\mathrm{KBr}$ were combined. A Nicolet 520P spectrometer was used with a resolution of $4 \mathrm{~cm}^{-1}$ and 64 scans per sample to record IR spectra $\left(4000-400 \mathrm{~cm}^{-1}\right)$. Some bands shielded by the extensive $\mathrm{OH}$ bending mode of bound water were elucidated using an FTIR spectrometer (BIO-RAD 175C) armed with an evacuation line. In this regard, the pellets were created with no $\mathrm{KBr}$. To press zein (about $4 \mathrm{mg}$ ), TM-nanoparticles and tribenuron-methyl specimens in a standard tool, a pressure of 98 $\mathrm{kN} \mathrm{cm}^{-2}$ was used to create pellets in diameter of $13 \mathrm{~mm}$ [35].

Entrapment efficacy (EE\%) and release of TM experiments Utilizing a UV-visible spectrophotometer (Agilent Technologies, Cary 60, USA), the quantity of TM entrapped within the developed nanoparticles was determined spectrophotometrically [36, 37]. Before determining TM content, a calibration curve was obtained for ethanolic TM solutions at various concentrations. The TM-loaded zein nanoparticles were then dissolved in $2 \mathrm{~mL}$ of ethanol and centrifuged at 15,000 rpm for $20 \mathrm{~min}$ (model 5415D, Eppendorf, Germany). By UV-Vis absorbance at $230 \mathrm{~nm}$, the TM content of the resultant supernatant solution was achieved. Ultimately, the encapsulation efficiency was determined (EE\%) (Eq. 1):

$$
\mathrm{EE}(\%)=\frac{\text { Amount of TM in the supernatant }}{\text { Total amount of TM used for formulation }} \times 100 .
$$

By dialysis method $[37,38]$ the release profile of TMloaded zein nanoparticles (TMZNP-5) was evaluated. $1 \mathrm{mg}$ at a concentration of $1 \mathrm{mg} \mathrm{mL}^{-1}$ of the TM-loaded nanoparticles was placed into dialysis bags and then
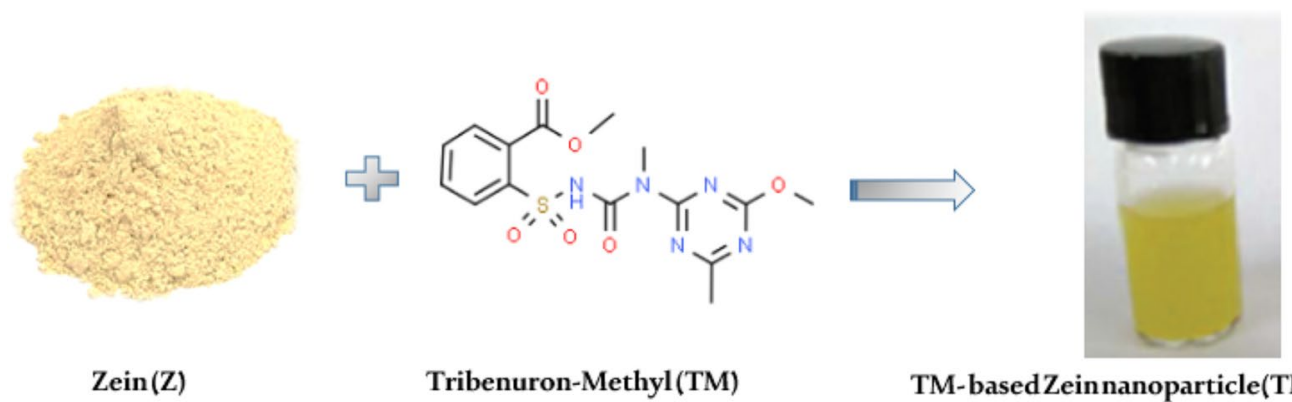

Tribenuron-Methyl(TM)

TM-basedZeinnanoparticle(TMZNP)

Scheme 1 Schematic diagram of the formation of TMZNP 
immersed in $30 \mathrm{~mL}$ PBS $(0.1 \mathrm{M} \mathrm{pH}=7)$ comprising $30 \%$ $(\mathrm{v} / \mathrm{v})$ ethanol for ensuring sink circumstances. For measurement, $1 \mathrm{~mL}$ of the release medium was withdrawn at specific time intervals and up to $168 \mathrm{~h}$ and replaced quickly by a fresh medium $(1 \mathrm{~mL})$. The control sample (the release profile of neat TM) was performed under similar circumstances. Via UV-Vis spectroscopy (a $230 \mathrm{~nm}$ wavelength), the samples were analyzed. By using the obtained standard calibration curve at PBS $0.1 \mathrm{M}$ $\mathrm{pH}=7$, the released drug concentration was determined. The results were stated as the cumulative release of 3 replicates.

\section{Planting and applying nanoparticles containing herbicides on plants}

The wheat seeds (cv. Pishgam) were soaked first with sodium hypochlorite for $10 \mathrm{~min}$ and washed with water. Mature seeds of $C$. arvensis were gathered from a naturally infested winter wheat field in Zanjan County (Iran) in summer 2019 and then kept at room temperature. The soil was taken from 0 to $20 \mathrm{~cm}$ depth in the research farm of the University of Zanjan, Iran (Table 1). The soil was sterilized at $121{ }^{\circ} \mathrm{C}$ and 1.5 atmospheres for $1 \mathrm{~h}$ after air drying. Planting the four seeds of $C$. arvensis in plastic trays $(25 \times 15 \times 25 \mathrm{~cm})$, they were kept for $3-4$ weeks at $4{ }^{\circ} \mathrm{C}$ for cold treatment for breaking the dormancy and enhancing germination. The trays were then moved to a greenhouse. When germination, seedlings were transplanted in $5 \mathrm{~kg}$ pots at the 2-3 leaf stage. They were grown in a greenhouse at $26 / 18{ }^{\circ} \mathrm{C}, 15 / 9 \mathrm{~h}$ a day/ night photoperiod with $60 \pm 10 \%$ relative humidity and $750 \mu \mathrm{mol} \mathrm{m}{ }^{-2} \mathrm{~s}^{-1}$ photosynthetic photon flux density.

To evaluate the efficacy of the new formulation, TMloaded zein nanoparticles (TMZNP-5) were sprayed on the C. arvensis plants reproduce by seed. Dry flowable (DF) commercial formulation of TM (Granstar) as well as untreated plants (not treated with herbicide) was also included for comparison. About $15 \mathrm{~mL}$ of a solution containing herbicide was utilized for each pot. Tribenuron-methyl solutions were employed with a laboratory sprayer armed with a flood-jet nozzle, calibrated for delivering $240 \mathrm{~L} \mathrm{ha}^{-1}$ at $210 \mathrm{kPa}$. Herbicide treatment was made when $C$. arvensis had 2-3 leaves. The experiments were performed by a completely randomized design (CRD) with eight replications.

\section{Data collection on plant traits}

Since ALS is the main target enzyme of the sulfonylurea family, the in vivo activities of ALS enzymes in mature leaves were assayed several days after treatment. ALS enzyme assays were performed as previously described [39]. Enzyme activity was determined based on the amount of acetoin formed from acetolactate using a wellestablished methodology [40]. Plant heights were calculated by the ruler at 14,21 , and 35 days after spraying. The fresh weight was measured by weighing the samples via a digital balance with an accuracy of $0.01 \mathrm{~g}$. The dry weight was measured by placing the plants for $48 \mathrm{~h}$ in an oven at $75^{\circ} \mathrm{C}$ and then weighting.

\section{Statistical analysis}

To analyze the data, SAS software (version 9.1) was used. The means were compared utilizing Duncan's multiple range test and analysis of variance (ANOVA) at the significance level of 0.05 .

\section{Results}

Zein nanoparticles' physicochemical characterization

DLS is extensively utilized for determining the size of the brown nanoparticles within colloidal suspensions in the nanoscale and micron range. The average size of zein nanoparticles was obtained using this method. DLS results showed an average size of $170 \mathrm{~nm}$ for TMZNP-5 (Fig. 1). Similar zein nanoparticle images were reported in other studies [30, 41, 42].

Thermal analysis is one of the common methods for determining compounds and investigating the thermal stability of materials [43, 44]. Figure 2 shows the TGA thermograms and their derivate (DTG) of neat zein and TMZNP-5. The neat zein showed two weight loss which the first one (below than $100{ }^{\circ} \mathrm{C}$ ) relates to physically adsorbed water molecules [45] and the second one (with $T_{\max }$ of $332{ }^{\circ} \mathrm{C}$ ) relates to the decomposition of the main structure of zein [46]. While for TMZNP-5, the main weight loss with $T_{\max }=332{ }^{\circ} \mathrm{C}$ same as the neat zein is observed indicating that the nature of zein had not been changed during the process of nanoparticles preparation. But a slow weight decreasing slope was observed starting from around $145^{\circ} \mathrm{C}$ which is consistent with TM decomposition temperature [47]. A weight loss of around 4.2 wt.\% was estimated for TM content in the final nanoparticles (Fig. 2).

Table 1 The soil characteristics of experiment site

\begin{tabular}{lllllll}
\hline Depth $(\mathbf{c m})$ & $\mathbf{p H}$ & $\left.\mathrm{EC}(\mathrm{dS} \mathrm{m})^{-1}\right)$ & Texture & $\boldsymbol{N}(\%)$ & $\mathbf{K}_{\left(\mathbf{m g ~ k g}^{-1}\right)}$ & $\boldsymbol{P}\left(\mathbf{m g ~ k g}^{-1}\right)$ \\
\hline $0-20$ & 7 & 0.9 & Loam & 0.5 & 301.8 & 20.33 \\
\hline
\end{tabular}




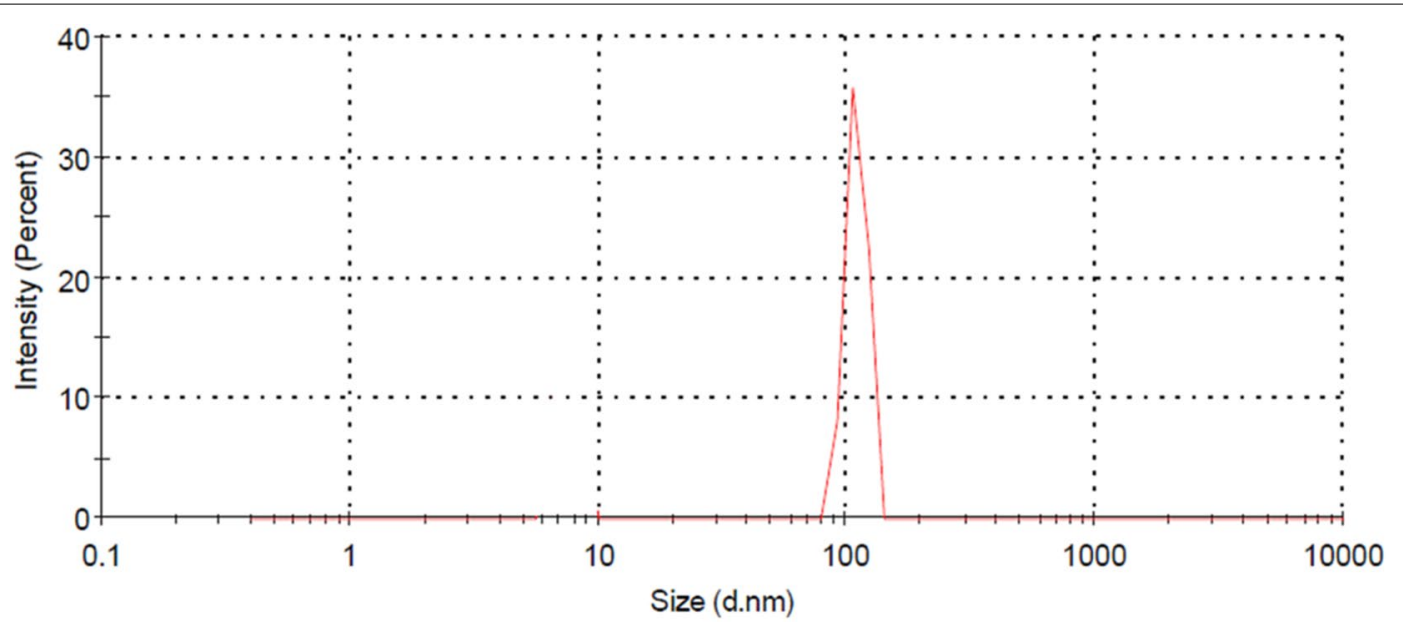

Fig. 1 Average hydrodynamic size of TM zein nanoparticles
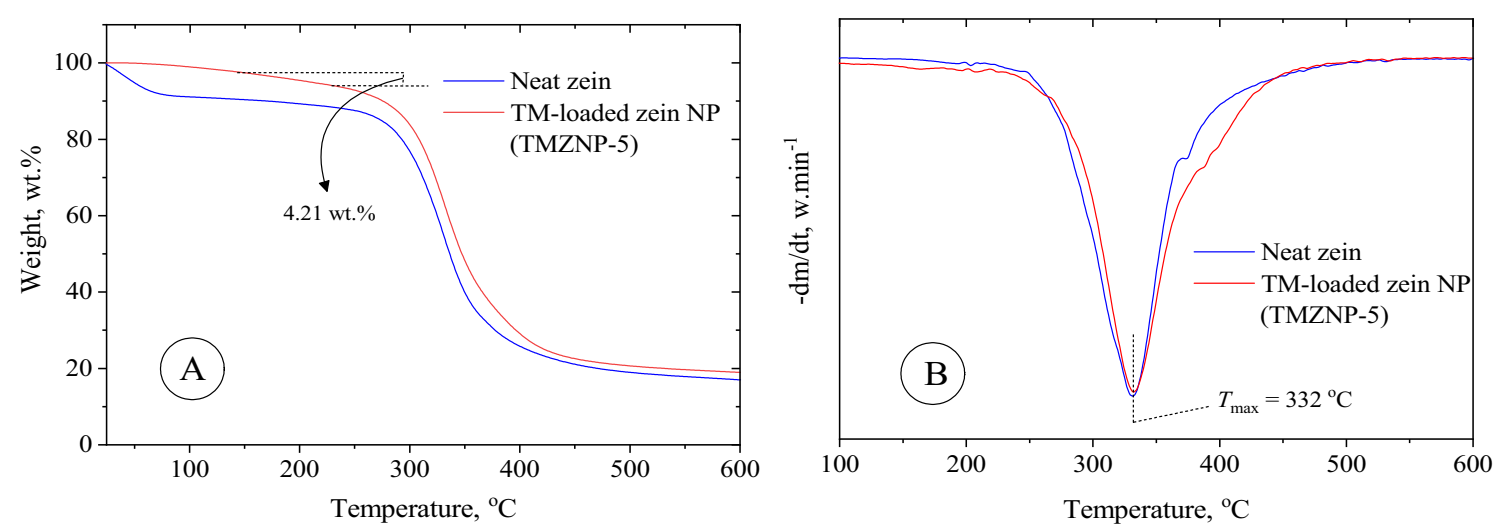

Fig. 2 TGA (A) and DTG (B) curves for zein and TM-loaded zein nanoparticles (TM2) at heating rate of $10^{\circ} \mathrm{C} \mathrm{min}^{-1}$ under $\mathrm{N}_{2}$ atmosphere

Figure 3 shows the SEM images of the TMZNPs to study their morphology. These images revealed spherical morphology with an approximately narrow size distribution. A size range of $80-120,100-180$, and $120-230 \mathrm{~nm}$, was estimated for TMZNP-2.4, TMZNP-5 and TMZNP10, respectively (Fig. 3). The increase in the size of the nanoparticles more likely relates to the increased TM content in the nanoparticles.

Figure 4 shows the FT-IR spectra of the neat zein and TMZNPs. The neat zein showed the characteristics peaks including stretching vibration of $-\mathrm{OH}$ of physically adsorbed water at $3100-3600 \mathrm{~cm}^{-1}$, stretching vibration of $\mathrm{C}-\mathrm{H}$ at $2850-2959 \mathrm{~cm}^{-1}$, and stretching vibration of $\mathrm{N}-\mathrm{H}$ of amide groups at $3071 \mathrm{~cm}^{-1}$. Moreover, the peaks at $1240,1307,1534$, and $1654 \mathrm{~cm}^{-1}$ were related to the amide III (axial deformation vibrations of $\mathrm{C}-\mathrm{N}$ stretching), amide II ( $\mathrm{N}-\mathrm{H}$ bending) and amide I $(\mathrm{C}=\mathrm{O}$ stretching vibration), respectively [47]. However, the FT-IR spectrum of TM is more crowded owing to the existence of various functional groups. The peaks at 2957 and $3104 \mathrm{~cm}^{-1}$ are associated with the stretching vibration of $\mathrm{C}-\mathrm{H}$ and $\mathrm{N}-\mathrm{H}$, respectively. The sharp peak at 1564 and $1731 \mathrm{~cm}^{-1}$ are correlated with the vibration of $\mathrm{C}=\mathrm{N}$ and $\mathrm{C}=\mathrm{O}$ in ester groups. The stretching vibrations at $1348 \mathrm{~cm}^{-1}$ are allocated for $\mathrm{S}=\mathrm{O}$ and ultimately the stretching vibration of $\mathrm{C}-\mathrm{O}$ of the ester group is found at $1268 \mathrm{~cm}^{-1}$ (Fig. 4) [48].

\section{Drug encapsulation and release}

The entrapment efficiency (EE\%) of TM inside the zein nanoparticles was measured. The entrapment efficiency (EE\%) of TM inside the TMZNP-5 was ca. $81 \% \pm 3$. The cumulative release of TM from TMZNP-5 (in vitro) was measured (Fig. 5). Dialysis bags comprising the TMZNP-5 were submerged in 

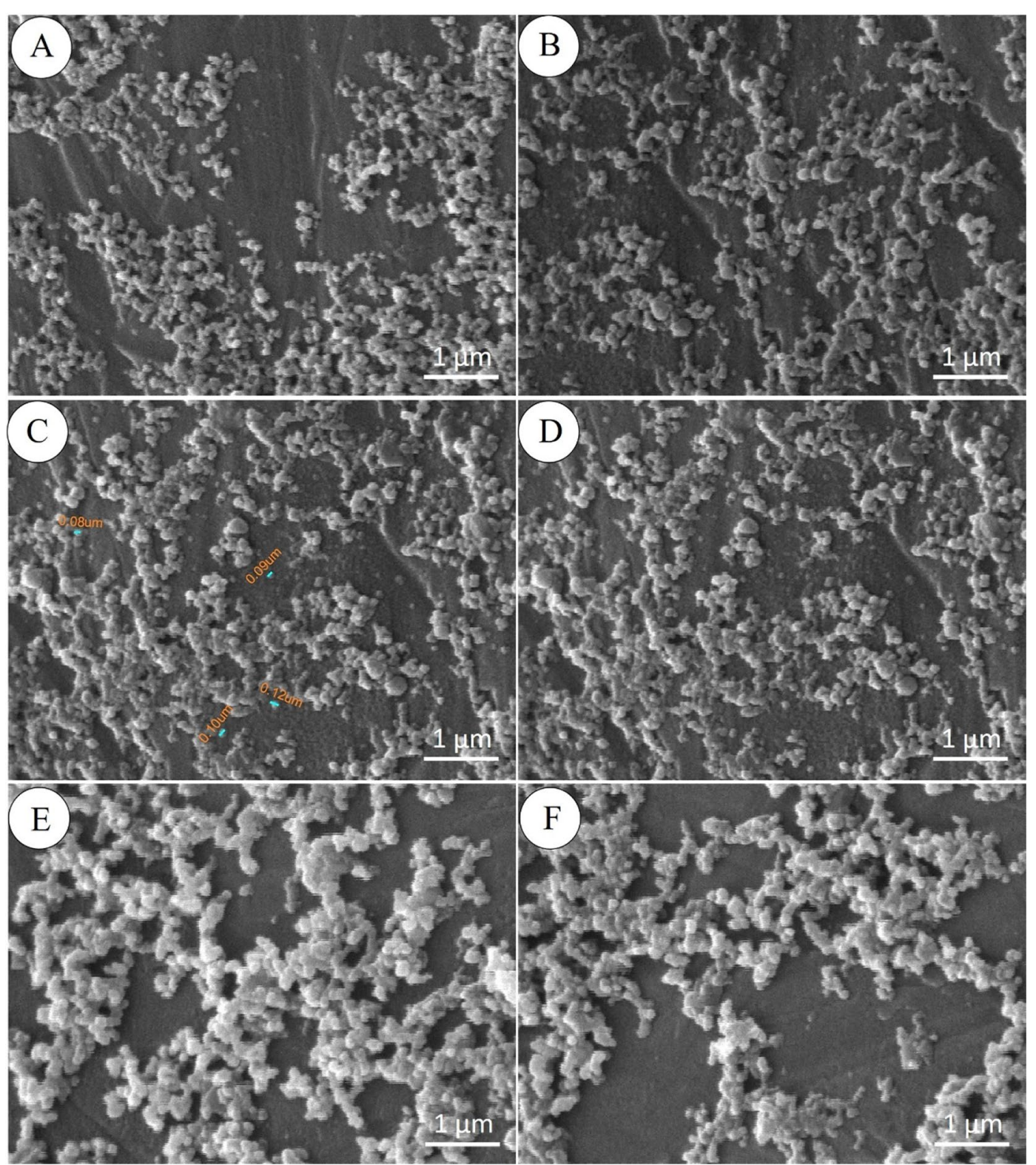

Fig. 3 SEM images for TMZNP-2.4 (A, B), TMZNP-5 (C, D) and TMZNP-10 (E, F)

PBS at pH 7 and $25^{\circ} \mathrm{C}$ for mimicking the physiological circumstances of the plant conditions. For comparison and control, the free TM release was also performed the release of TM from the TMZNP-5 was biphasic, with a burst release phase within the first $5 \mathrm{~h}$ after the trend was fixed and a more sustained pattern. Almost $50 \%$ of TM was released from the nanoparticles after $40 \mathrm{~h}$, while during first $5 \mathrm{~h}$ free TM was completely released (Fig. 5).
Effect on physiological and morphological traits of weed

Analysis of variance indicated positive effects of using biopolymer-based nanoparticles and commercial TM on physiological and morphological characteristics of C. arvensis (Table 2). The results of Table 2 show the significant effects $(P \leq 0.01)$ of biopolymer-based nanoparticles on the ALS enzyme activity, plant height, fresh and dry weight of $C$. arvensis (Table 2). 

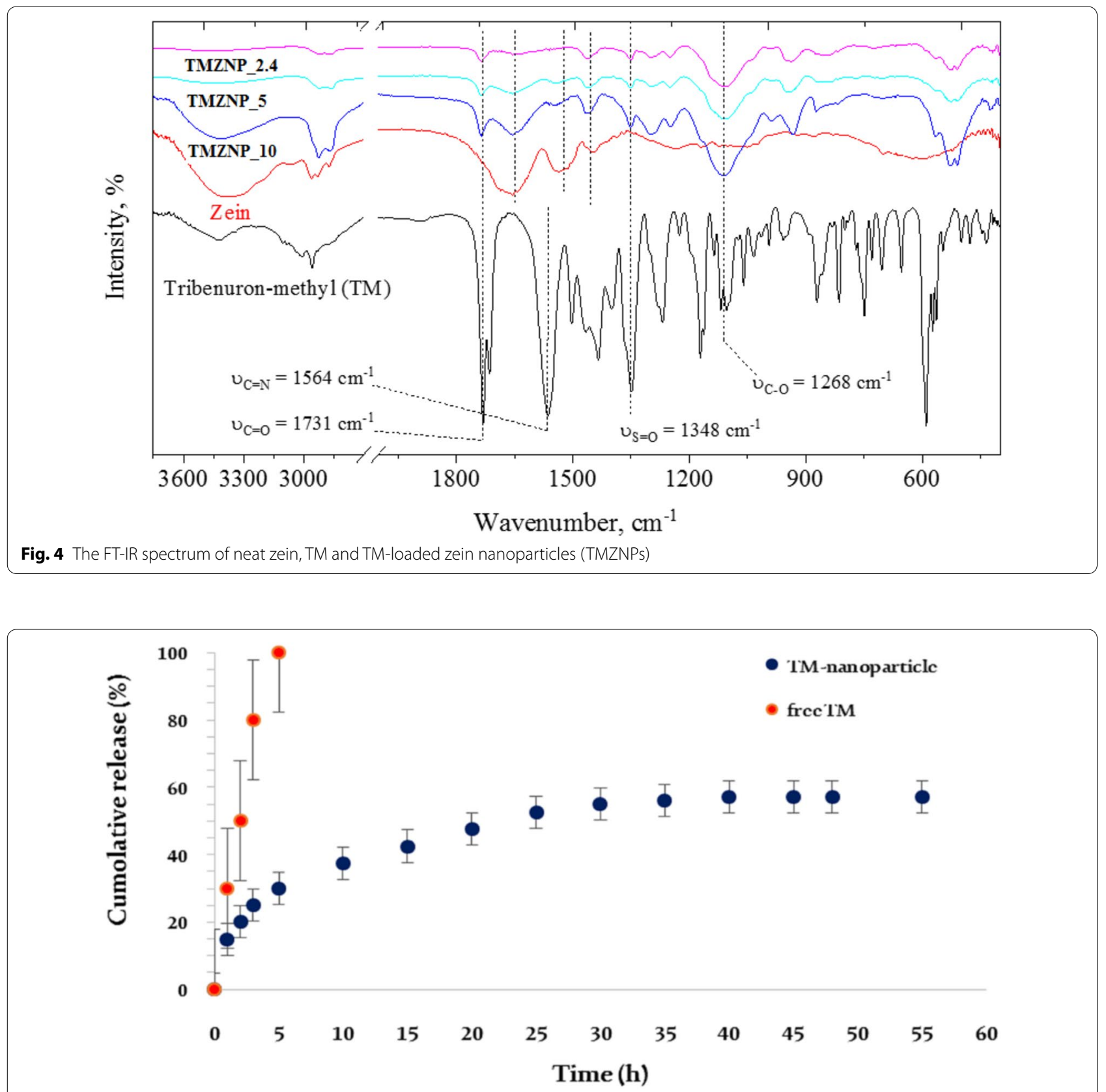

Fig. 5 Release profiles of TM-loaded and TM-free biopolymer-based nanoparticles (TMZNP-5)

The results of morphological and physiological features of weed are shown in Fig. 6. The highest ALS

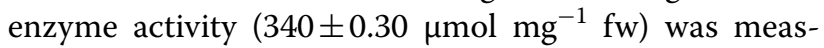
ured in the untreated plants while TMZNP-5 application decreased it to $61 \pm 0.20 \mu \mathrm{mol} \mathrm{mg}^{-1} \mathrm{fw}$ (Fig. 6A). Considering the high ALS activity variability in various treatments, further ALS assays were performed utilizing tissues of the same developmental stage, which were chosen carefully, i.e., young developing tissue. In plants treated with TMZNP-5, the ALS activity was significantly decreased by $82 \%$. While in plants treated with the commercial TM, ALS enzyme activity was obtained approximately $48 \mu \mathrm{mol} \mathrm{mg}^{-1} \mathrm{fw}$. However, commercial TM and TMZNP-5 treatments were included in a common statistical group.

The highest weed height $(97.5 \mathrm{~cm})$ was observed from untreated plants (Fig. 6). The application of TMZNP-5 and commercial TM reduced plants height by 77 and 
Table 2 Analysis of variance the effects of experimental treatment on the ALS enzyme activity, plant height, fresh and dry weight of $C$. arvensis

\begin{tabular}{llllllllll}
\hline MS & \multicolumn{1}{l}{ A.O.V } & df & ALS & Dw1 & Dw2 & Dw3 & Fw1 & Fw2 & Fw3 \\
\hline Treatment & 2 & $217,698.66^{* *}$ & $59.7636^{* *}$ & $1042.165^{* *}$ & $519.545^{* *}$ & $1129.470^{* *}$ & $4377.935^{* *}$ & $17,950.335^{* *}$ & $15,790.627^{* *}$ \\
Error & 21 & 5.8333 & 0.055561 & 0.207221 & 0.310208 & 0.261980 & 0.32398 & 0.36041 & 0.11375 \\
F value & - & $37,319.8$ & 1075.54 & 5029.25 & 1674.83 & 4311.28 & $13,513.0$ & $49,805.1$ & 138,819 \\
CV & - & 1.61 & 7.04 & 3.68 & 3.48 & 4 & 2.25 & 1.17 & 1.72 \\
\hline
\end{tabular}

Dw: dry weight; Fw: fresh weight; ${ }^{\text {ns }}$ not significant

* Significant at $5 \%$ probability level; and ${ }^{* *}$ significant at $1 \%$ probability level
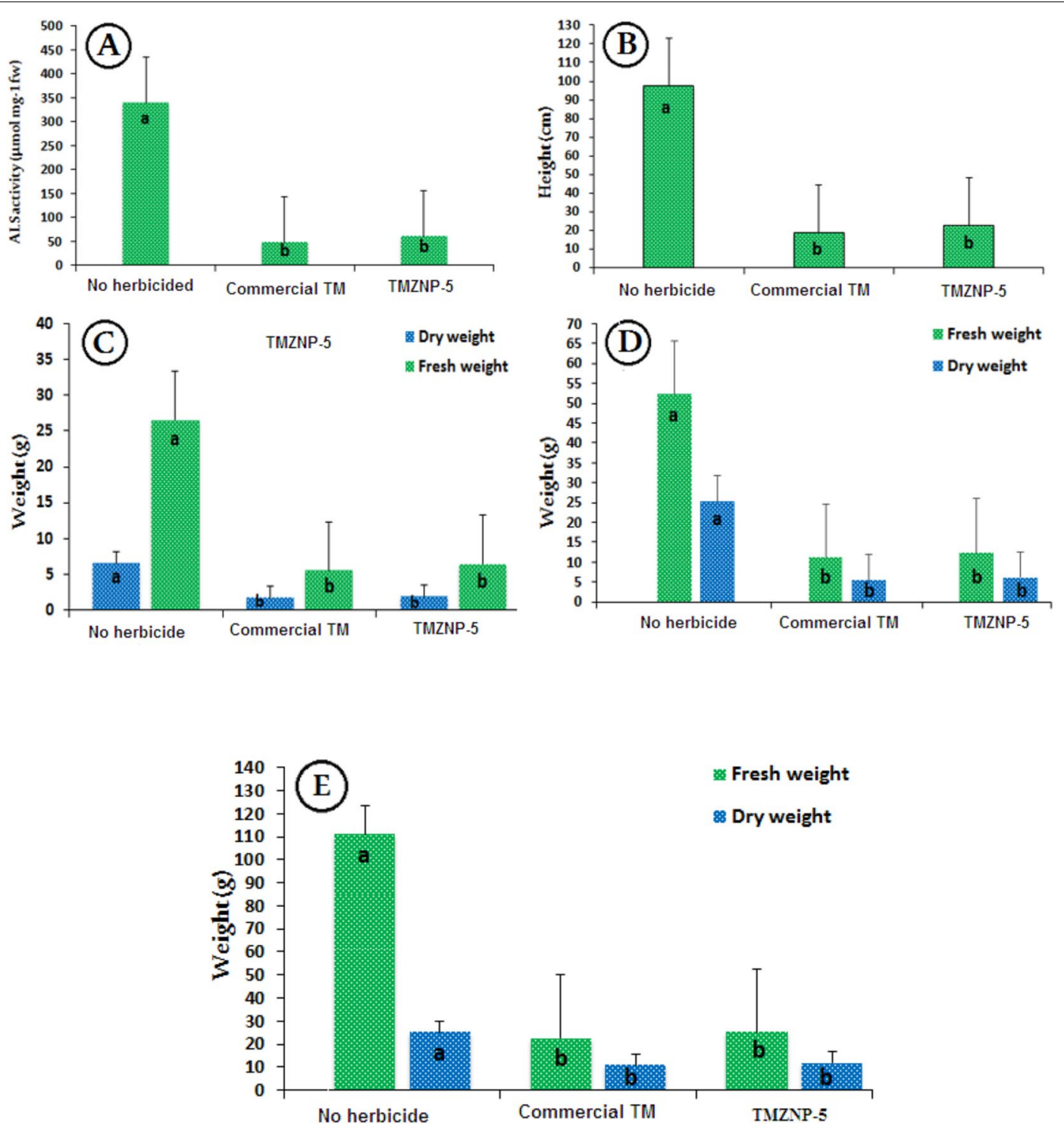

Fig. 6 Mean of comparing the impacts of various treatment (TM: tribenuron-methyl; TMZNP-5: tribenuron-methyl zein-based nanoparticles) on the ALS activity (A), plant height (B), fresh weight, and dry weight of C. arvensis at first sampling $(\mathbf{C})$, second sampling (D), and third sampling (E). Columns with different letters are significantly different based on Duncan's multiple range test $(P<0.05)$ 
$81 \%$, respectively. Biopolymer-based nanoparticles containing tribenuron-methyl at $15 \mathrm{~g}$ a.i. ha ${ }^{-1}$ significantly reduced dry weight of $C$. arvensis compared to untreated plants by 71,75 , and $53 \%$ at 2,3 , and 5 weeks after spraying, respectively (Fig. 6). This treatment also reduced the fresh weight of weed compared with the control by $76 \%$ at three samplings (Fig. 6). Although commercial tribenuron-methyl represents the relatively less fresh weight and dry weight than TMZNP-5, no statistically significant differences were found between the performances of these two treatments.

\section{Discussion}

As mentioned above, DLS results showed an average size of $170 \mathrm{~nm}$ for TMZNP-5, and also based on the SEM result, the approximate size of the nanoparticles was in the range of $80-120 \mathrm{~nm}$, which indicates good results for zein nanoparticles and was consistent with the results of former studies [42-47].

The results of FTIR appearance of the main distinctive peaks of zein and TM in the spectrum of all the TMZNPs indicate a higher ability of zein nanoparticles to encapsulate TM molecules.

The encapsulation efficiency (EE\%) is one of the key physicochemical factors of nanocarriers. Reducing potential side effects requires ensuring high encapsulation efficiencies which are achieved with the herbicidal effectiveness of the loaded agents at lower concentrations compared to the case of administered free bioactive compounds $[47,48]$. The obtained higher EE\% may be associated with the interactions between TM and the zein molecules [30]. Moreover, the herbicide release profile and its rate are other characteristics for nanocarriers.

With the application of TM loaded to zein-based nanoparticles, the activity of ALS enzyme decreased by $82 \%$. TM is insoluble in water, due to strong intermolecular bonds [49]. Loading active ingredients to zein-based nanoparticles resulted in increased dissolution and dispersion in the water [30]. It is likely that loading TM to zein nanoparticles increased the solubility and dispersing rate of the active ingredients in the tank, and as a result plants uptake more herbicide. The application of TMZNP-5 reduced plants height by $77 \%$. Also, TMZNP-5 reduced the plant's dry and fresh weight in comparison with other treatments. The decrease of weed height and dry weight can be caused by the higher solubility of nanoparticles in water and ultimately greater uptake by the weed, which causes the inhibiting of the ALS enzyme and decreasing the activity of the enzyme causing reduced biosynthesis of the amino acids valine and leucine that ultimately prevents protein biosynthesis [39], which in turn prevents cell division in the plant. As a result, it reduces the growth of weed and reduces height, and dry weight. Due to the fact that the concentration of tribenuron-methyl used in TMZNP-5 was approximately $1 / 2$ of the recommended dose of commercial tribenuron-methyl, the results were very favorable for the performance of these nanoparticles. According to the zein-based nanoparticles form represented considerably higher dispersibility and solubility of an ingredient than the crude zein in water suspension [30]. In small-scale herbicides (nano and micro) and colloidal, which are essentially water-soluble, the rate of uniform dissolution and dispersion increases [39]. On the other hand, due to their unique conditions, nanoparticles have the ability to trap various ions and gradually release them into the plant. Therefore, the use of TMZNP-5 improved the solubility of this insoluble herbicide in water and consequently increased its uptake and efficiency. In addition, as the size of the herbicide decreases and the surface-to-volume ratio increases, more solubility, and more uptake can be the main reasons for the significant reduction in plant height, fresh and dry weight in the weed. These findings can be clarified by inhibiting TM insolubilization owing to nanoparticles, leading to the reduced molecular mobility of the TM and therefore the enhanced dispersibility or solubility of the entrapped TM. Particularly, the TM solubility was enhanced by zein hydrophilicity [50]. It is indicated that TM dispersibility and solubility are incremented by TMZNP-5. Moreover, zein nanoparticles have a key role in enhancing the solubility of TM.

\section{Conclusion}

$\mathrm{TM}$ is one of the most commonly used selective herbicides for control of broad-leaf weeds in cereals mainly wheat, barley and, triticale. However, poor water solubility limits its applications. Zein could provide alternative encapsulation carriers to deliver nutritional and functional components. In the present work, zein-based nanoparticles containing the TM were prepared. DLS results showed an average size of $170 \mathrm{~nm}$ for TMZNP5. According to the SEM result, the approximate size of the nanoparticles is within the range of $80-120 \mathrm{~nm}$. The TM's drug encapsulation efficiency within the nanoparticles was ca. $81 \% \pm 3$. Based on in vitro cumulative drugrelease profile, the developed nanoparticles enable a more controlled and sustained release of the loaded drug. The use of nanoparticles containing tribenuron-methyl (TMZNP-5) had a significant effect on weed growth and TMZNP- 5 was able to completely suppress the $C$. arvensis. Overall, encapsulation of tribenuron-methyl caused more solubility in water, slower release, more absorption, and eventually increased TM bioactivity. These findings indicate that zein nanoparticles can be potentially utilized as nanocarriers for enhancing the solubility of TM, 
which can further enhance its performance and bioavailability on weeds.

\section{Abbreviations}

TM: Tribenuron-methyl; TMZNP: Tribenuron-methyl-based zein nanoparticle.

\section{Acknowledgements}

Not applicable.

\section{Authors' contributions}

ARY designed and supervised the experiment. MS performed the greenhouse and laboratory workload and wrote the first manuscript draft. NN analyzed the data. AR gave scientific advice and practical laboratory helps. GK, MB, all authors revised and edited the manuscript. All authors read and approved the final manuscript.

\section{Funding}

The authors greatly thank the University of Zanjan, for financial support for this work.

\section{Availability of data and materials}

Are available on request.

\section{Declarations}

Ethics approval and consent to participate

All authors listed have contributed significantly to the research and agree to be in the author list.

\section{Consent for publication}

All authors agree to publish the work.

\section{Competing interests}

No competing of interests was declared regarding the content of this paper.

\section{Author details}

'Department of Plant Production \& Genetics, University of Zanjan, 4537138791 Zanjan, Iran. ${ }^{2}$ Department of Chemistry, Institute for Advanced Studies in Basic Sciences (IASBS), 45137-66731 Zanjan, Iran. ${ }^{3}$ Department of Physics, Faculty of Science, University of Zabol, P.O. Box. 98613-35, Zabol, Iran. ${ }^{4}$ Department of Chemistry, International Hellenic University, Kavala, Greece. ${ }^{5}$ School of Life Science and Food Engineering, Huaiyin Institute of Technology, Huaian 223003, China.

Received: 10 July 2021 Accepted: 2 September 2021 Published online: 28 October 2021

\section{References}

1. Kraehmer H, Baur P. Weed anatomy. Hoboken: Wiley; 2013.

2. Catton HA, Lalonde RG, Buckley YM, De Clerck-Floate RA. Biocontrol insect impacts population growth of its target plant species but not an incidentally used nontarget. Ecosphere. 2016;7(5):e01280.

3. Zewerger P, Ammon HU. Unkrut: Okologie and Bakampfung. Stuttgart: Eugen Ulmer; 2002

4. Melander B. Impact of drilling date on Apera spica-venti L. and Alopecurus myosuroides Huds, in winter cereals. Weed Res. 1995;35(3):157-66.

5. Hay JV. Chemistry of sulfonylurea herbicides. Pestic Sci. 1990;29(3):247-61.

6. Tomlin C. The Pesticide Manual tenth edition edited by Clive Tomlin, Published by the Royal Society of Chemistry and the British Crop Protection Council, Farnham, Surrey, UK. 1994.

7. Blair AM, Martin TD. A review of the activity, fate and mode of action of sulfonylurea herbicides. Pestic Sci. 1988;22:195-219.

8. Sarmah AK, Sabadie J. Hydrolysis of sulfonylurea herbicides in soils and aqueous solutions: a review. J Agric Food Chem. 2002;50:6253-65.
9. Cobb AH, Reade JP. Herbicides and plant physiology. Hoboken: Wiley; 2011.

10. Vauthier $\mathrm{C}$. Formulating nanoparticles to achieve oral and intravenous delivery of challenging drugs. In NanoFormulation, 2012; 1-19.

11. Farokhzad OC, Langer R. Impact of nanotechnology on drug delivery. ACS Nano. 2009;3(1):16-20.

12. Herault D. Encapsulation of emulsions, PCT Application WO2002051536. 2002.

13. Yu MK, Park J, Jon S. Targeting strategies for multifunctional nanoparticles in cancer imaging and therapy. Theranostics. 2012;2(1):3-11.

14. Sasson Y, Levy-Ruso G, Toledano O, Ishaaya I. Nanosuspensions: emerging novel agrochemical formulations. In: Insecticides design using advanced technologies. Springer; 2007, 1-39

15. Andreta E. Nano sciences and nano technologies: what future for research. Paper presented at the Future Conference and Expo, Chiba-shi, Chiba, Tokyo, Japan. 2003.

16. Heydari M, Mir N, Moussavi-Nik SM. Reducing nitrogen loss by application of natural clinoptilolite modified with quaternary N-Alkyl agent as controlled-release fertilizer in two species of beans ( . vulgaris and Vigna Unguiculata). Commun Soil Sci Plant Anal. 2018;49(13):1586-603.

17. Heydari M, Yousefi AR, Rahdar A, Nikfarjam N, Jamshidi K, Bilal M, Taboada P. Microemulsions of tribenuron-methyl using Pluronic F127: physicochemical characterization and efficiency on wheat weed. J Mol Liq. 2021;326:115263.

18. Reddy N, Yang Y. Potential of plant proteins for medical applications. Trends Biotechnol. 2011;29:490-8.

19. Lasic DD, Papahadjopoulos D. Liposomes, and biopolymers in drug and gene delivery. Curr Opin Solid State Mater Sci. 1996;1:392-400.

20. Paliwal R, Palakurthi S. Zein in controlled drug delivery and tissue engineering. J Control Release. 2014;189:108-22.

21. Jahanshahi M, Babaei Z. Protein nanoparticle: a unique system as drug delivery vehicles. Afr J Biotechnol. 2008; 7.

22. Hawkins MJ, Soon-Shiong P, Desai N. Protein nanoparticles as drug carriers in clinical medicine. Adv Drug Deliv Rev. 2008;60:876-85.

23. Muthuselvi L, Dhathathreyan A. Simple coacervates of zein to encapsulate gitoxin. Colloids Surf B: Biointerfaces. 2006;51:39-43.

24. Hurtado-Lopez P, Murdan S. Zein microspheres as drug/antigen carriers: a study of their degradation and erosion, in the presence and absence of enzymes. J Microencapsul. 2006;23:303-14.

25. Wu Y, Luo Y, Wang Q. Antioxidant and antimicrobial properties of essentia oils encapsulated in zein nanoparticles prepared by liquid-liquid dispersion method. LWT-Food Sci Technol. 2012;48(2):283-90.

26. Xue F, Li C, Liu Y, Zhu X, Pan S, Wang L. Encapsulation of tomato oleoresin with zein prepared from corn gluten meal. J Food Eng. 2013;119(3):439-45

27. Labib G. Overview on zein protein: a promising pharmaceutical excipient in drug delivery systems and tissue engineering. Expert Opin Drug Deliv. 2018;15(1):65-75.

28. Shukla R, Cheryan M. Zein: the industrial protein from corn. Ind Crop Prod. 2001;13:171-92.

29. Liu C, Yao W, Zhang L, Qian H, Wu W, Jiang X. Cell-penetrating hollow spheres based on milk protein. Chem Commun. 2010;46:7566-8.

30. Jiao Y, Zheng X, Chang Y, Li D, Sun X, Liu X. Zein-derived peptides as nanocarriers to increase the water solubility and stability of lutein. Food Funct. 2018;9(1):117-23.

31. Cieśla J, Koczańska M, Narkiewicz-Michałek J, Szymula M, Bieganowski A. Effect of a-tocopherol on the properties of microemulsions stabilized by the ionic surfactants. J Mol Liq. 2017;236:117-23.

32. Cieśla J, Koczańska M, Narkiewicz-Michałek J, Szymula M, Bieganowski A. The physicochemical properties of CTAB solutions in the presence of a-tocopherol. J Mol Liq. 2016;222:463-70.

33. Liang J, Li F, Fang Y, Yang W, An X, Zhao L, Xin Z, Hu Q. Response surface methodology in the optimization of tea polyphenols-loaded chitosan nanoclusters formulations. Eur Food Res Technol. 2010;231(6):917-24.

34. Luo Y, Wang TT, Teng Z, Chen P, Sun J, Wang Q. Encapsulation of indole3-carbinol and 3, 3'-diindolylmethane in zein/carboxymethyl chitosan nanoparticles with controlled release property and improved stability. Food Chem. 2013;139(1-4):224-30.

35. Zou LQ, Liu W, Liu WL, Liang RH, Li T, Liu CM, Cao YL, Niu J, Liu Z. CharaCterization and bioavailability of tea polyphenol nanoliposome prepared 
by combining an ethanol injection method with dynamic high-pressure microfluidization. J Agric Food Chem. 2014;62:934-41.

36. Chuacharoen T, Sabliov CM. Stability and controlled release of lutein loaded in zein nanoparticles with and without lecithin and pluronic F127 surfactants. Colloids Surf A. 2016;503:11-8.

37. Basiri L, Rajabzadeh G, Bostan A. a-Tocopherol-loaded niosome prepared by heating method and its release behaviour. Food Chem. 2017;221:620-8.

38. Modi S, Anderson BD. Determination of drug release kinetics from nanoparticles: overcoming pitfalls of the dynamic dialysis method. Mol Pharm. 2013;10:3076-89.

39. Schloss JV. Modern aspects of enzyme inhibition with particular emphasis on reaction intermediate analogs and other potent, reversible inhibitors. In: Boger P, Sandmann G, editors. Target Sites of Herbicide Action. Boca Raton: CRC Press; 1989. p. 165-245.

40. Liu XQ, Yu CY, Dong JG, Hu SW, Xu AX. Acetolactate synthase-inhibiting gametocide amidosulfuron causes chloroplast destruction, tissue autophagy, and elevation of ethylene release in rapeseed. Front Plant Sci. 2017:8:1625.

41. Parris N, Cooke PH, Hicks KB. Encapsulation of essential oils in zein nanospherical particles. J Agric Food Chem. 2005;53(12):4788-92.

42. Zhang Y, Niu Y, Luo Y, Ge M, Yang T, Yu LL, Wang Q. Fabrication, characterization and antimicrobial activities of thymol-loaded zein nanoparticles stabilized by sodium caseinate-chitosan hydrochloride double layers. Food Chem. 2014;142:269-75.

43. Ismail K, Zakaria Z, Ishak MAM. Thermal behaviour study of Mukah Balingian coal and biomass blend during pyrolysis via thermogravimetric analysis. In: Paper Presented at the 22nd International Pittsburgh Coal Conference, Pittsburgh USA. 2005.
44. Vuthaluru H. RETRACTED: Investigations into the pyrolytic behaviour of coal/biomass blends using thermogravimetric analysis. In: Elsevier. 2004

45. Lide D.R. Handbook of Chemistry and Physics (77th edition). CRC Press: London, 1996-1997.

46. Magoshi J, Nakamura S, Murakami Kl. Structure and physical properties of seed proteins. I. Glass transition and crystallization of zein protein from corn. J Appl Polym Sci. 1992;45(11):2043-8.

47. Moradkhannejhad L, Abdouss M, Nikfarjam N, Mazinani S, Heydari V. Electrospinning of zein/propolis nanofibers; antimicrobial properties and morphology investigation. J Mater Sci - Mater Med. 2018;29(11):1-10.

48. Manzoor S, Ansari TM, Arslan M, Intizar A, Fatima A, Mujahid M, Hanif MA. Araucaria heterophylla resin-coated magnetic nanosorbent: a greener approach for the abatement of Mesotrione and Metsulfuron methyl herbicides. International Journal of Environmental Analytical Chemistry, 2020; 1-13.

49. Saari LL. Resistance to acetolactate synthase inhibiting herbicides. In: Powles SB, Holtum JAM, editors. Herbicide resistance in plants biology and biochemistry. Boca Raton: Lewis Publishers; 1994. p. 83-140.

50. Vasconcelos T, Sarmento B, Costa P. Solid dispersions as strategy to improve oral bioavailability of poor water soluble drugs. Drug Discov Today. 2007;12(23-24):1068-75.

\section{Publisher's Note}

Springer Nature remains neutral with regard to jurisdictional claims in published maps and institutional affiliations.

\section{Submit your manuscript to a SpringerOpen ${ }^{\circ}$ journal and benefit from:}

- Convenient online submission

- Rigorous peer review

- Open access: articles freely available online

- High visibility within the field

- Retaining the copyright to your article

Submit your next manuscript at $\boldsymbol{\nabla}$ springeropen.com 